University of Nebraska - Lincoln

DigitalCommons@University of Nebraska - Lincoln

Papers in Construction Management

Construction Systems

2012

\title{
A case-crossover study of laceration injuries in pork processing
}

Lina Lander

University of Nebraska Medical Center, Ilander@unmc.edu

Gary Sorock

Springfield Hospital Center, Sykesville, Maryland,

Terry L. Stentz

University of Nebraska-Lincoln, tstentz2@unl.edu

Lynette Smith

University of Nebraska Medical Center, Imsmith@unmc.edu

Murray Mittleman

Harvard School of Public Health, mmittlem@hsph.harvard.edu

See next page for additional authors

Follow this and additional works at: https://digitalcommons.unl.edu/constructionmgmt

Part of the Construction Engineering and Management Commons

Lander, Lina; Sorock, Gary; Stentz, Terry L.; Smith, Lynette; Mittleman, Murray; and Perry, Melissa J., "A case-crossover study of laceration injuries in pork processing" (2012). Papers in Construction Management. 8.

https://digitalcommons.unl.edu/constructionmgmt/8

This Article is brought to you for free and open access by the Construction Systems at DigitalCommons@University of Nebraska - Lincoln. It has been accepted for inclusion in Papers in Construction Management by an authorized administrator of DigitalCommons@University of Nebraska - Lincoln. 


\section{Authors}

Lina Lander, Gary Sorock, Terry L. Stentz, Lynette Smith, Murray Mittleman, and Melissa J. Perry 


\title{
A case-crossover study of laceration injuries in pork processing
}

\author{
Lina Lander, ${ }^{1}$ Gary Sorock, ${ }^{2}$ Terry L. Stentz, ${ }^{3,4}$ Lynette M. Smith, ${ }^{5}$ \\ Murray Mittleman, ${ }^{6,7}$ and Melissa J. Perry 7,8
}
1. Department of Epidemiology, University of Nebraska Medical Center, Omaha, Nebraska, USA
2. Springfield Hospital Center, Sykesville, Maryland, USA
3. College of Engineering, University of Nebraska-Lincoln, Lincoln, Nebraska, USA

4. Department of Environmental, Agricultural and Occupational Health, University of Nebraska Medical Center, Nebraska USA

5. Department of Biostatistics, University of Nebraska Medical Center, Omaha, Nebraska, USA

6. Department of Epidemiology, Harvard School of Public Health, Boston, Massachusetts, USA

7. Department of Environmental Health, Harvard School of Public Health, Boston, Massachusetts, USA

8. Department of Environmental and Occupational Health, The George Washington University, Washington, DC, USA

Corresponding author - Dr. Lina Lander, Assistant Professor, Department of Epidemiology, College of Public Health, University of Nebraska Medical Center, 984395 Nebraska Medical Center, Omaha, NE 68198-4395, USA; email llander@unmc.edu

\section{ABSTRACT}

Objectives - The authors estimated the associations between transient risk factors and laceration injuries in workers at two meatpacking plants in the Midwest.

Methods - The case-crossover design was used to collect within-subject transient work task and personal-level exposure information. RRs of laceration injuries were estimated by comparing exposures during the 'hazard' period (just before the laceration injury) with exposures in the 'control' period (the previous workweek). Stratified analyses were utilized to estimate the effects of gender, ethnicity, training and the number of adjacent coworkers on each transient risk factor.

Results - The authors interviewed 295 meatpacking workers with laceration injuries (mean age 36.6 years, SD 11.2, 75\% men, 48\% Hispanic). Recent tool sharpening (RR 5.3, 95\% Cl 3.8 to 7.4 ) and equipment malfunction (RR $5.3,95 \% \mathrm{Cl} 3.9$ to 7.3 ) were associated with the highest RR for laceration injury, followed by using an unusual work method to accomplish a task (RR 4.1, 95\% Cl 2.6 to 6.4) and performing an unusual task (RR 2.3, 95\% Cl 1.8 to 3.0). Rushing and being distracted were not significantly associated with an elevated RR of a laceration injury. In stratified analyses, there were a number of significant differences in laceration risk factors by gender, ethnicity, training, and number of workers on the line.

Conclusions - Sharpening tools, equipment malfunction, using an unusual work method to accomplish a task and performing an unusual task were all associated with increased risk of lacerations. Expanded training in atypical work circumstances and evaluation of tool sharpening procedures are intervention areas in meatpacking that need examination.

\section{What this paper adds}

- Our results confirm our prior preliminary findings that sharpening tools, equipment malfunction, using an unusual work method to accomplish a task and performing an unusual task are important risk factors for laceration injuries in this line-paced work environment.

- These transient risk factors vary by gender, ethnicity, training and number of workers on the line.

- We observed high personal protective equipment compliance at the time of the injury.

- Detailed analysis of sharpening protocols, expanded training in unusual work circumstances and sources of personal protective equipment failure are all needed to effectively reduce laceration injuries in the meatpacking industry.

\section{INTRODUCTION}

The US animal slaughtering and processing industry employed approximately 500,000 workers in 2009. ${ }^{.}$The Bureau of Labor Statistics incidence rate of nonfatal occupational injuries and illnesses for Animal Slaughtering and Processing (North American Industry Classification System code $=31161$ ) was 6.9 per 100 full-time workers in 2009, one of the highest industry rates nationwide. ${ }^{1}$

Occupational upper extremity acute trauma is characterized by sudden transfer of high-energy forces to susceptible skin and underlying tissues of the fingers, hand, wrist and arm while at work. ${ }^{2}$ The resulting injuries may include laceration, sprain/strain, contusion, puncture, dislocation, crush, amputation, avulsion, burn, or foreign body. Meatpacking is one of the most hazardous industries in the USA. The incidence rate of nonfatal occupational injuries and illnesses was 6.9 per 100 full-time workers in 2009. A workers' compensation provider estimated that $33 \%$ of all claims were for upper extremity trauma. ${ }^{3}$ The National Electronic Injury Surveillance System found that of approximately 3.6 million occupational injuries treated in US emergency departments in $1998,25 \%$ were for injuries to the upper extremities such as hands and fingers and $22 \%$ were lacerations. ${ }^{4}$ One case-crossover study of 1166 occupational traumatic injuries in New England found that lacerations constituted the most common injury type in both women $(58 \%)$ and men $(64 \%) .5$

The research literature on laceration injuries in meatpacking workers has been limited to one cross-sectional and one cohort study. The first found that among two plants, laceration rates were higher in the one doing more slaughter and hide removal than the other prant. ${ }^{6}$ The second study also found higher injury rates in tasks requiring more frequent harvesting and cutting operations. 7 To better characterize the context of these injuries, studies are needed that explore transient modifiable risk factors for injury in meatpacking. ${ }^{2}$ This study utilized a case-crossover design to estimate the incidence of laceration injuries associated 
with transient risk factors at two meatpacking piants. ${ }^{8}$ We evaluated the risk of laceration injury associated with knife or tool sharpening, performing an unusual task, using an unusual work method, equipment malfunction, and worker-related exposures such as rushing, being distracted, being tired, slipping, and falling. These factors were selected based on a previous study of occupational hand injuries 5,9 and lacerations. ${ }^{10}$ Transient risk factors were targeted because they are amenable to preventive interventions. This paper expands on the previously reported methods and preliminary results of this study by including results from the complete data analyses. ${ }^{8}$ Our sample size has almost doubled, allowing for adequate power to conduct stratified analyses of transient factors by potential effect modifiers including gender, ethnicity, safety training, and number of workers on the line, hours worked per week, and use of metal mesh gloves at the time of injury. In addition, we analyzed the use of required personal protective equipment (PPE) immediately before the injury. Finally, we examined the self-reported reasons for injury, tools used, and explanations of transient exposures in the narrative text section of the questionnaire in order to extend the full results of this study and to better contextualize the circumstances surrounding actual injury events.

\section{METHODS}

The detailed methodology for this case-crossover study has been reported previously. ${ }^{8}$ Briefly, study participants were recruited from two pork-processing plants, one in Nebraska (1995 employees) and one in Iowa (1300 employees). Eligible study participants included plant-floor workers (including maintenance staff) at risk for laceration injuries from sharp objects. Excluded workers were those who did not speak English or Spanish or did not have contact with floor operations, such as office or loadingdock workers. Workers who experienced a laceration injury and were eligible to participate were identified when they came to the plant-based occupational health clinic for treatment of their injury. Those who expressed an interest in participating were contacted by either an English- or a Spanish-speaking trained interviewer who described the research study and answered the participant's questions. Informed consent was obtained by telephone. The interviewer then administered a structured questionnaire including questions on fixed demographic and worksite characteristics and transient exposures of interest.

Occupational exposures that change over time or transient risk factors that increase (or decrease) injury risk over the course of the week were the focus of this study. ${ }^{9,11}$ In this case-crossover study, we defined the "hazard" period to be "just before the laceration injury" and the "control" period as "the previous workweek" in order to estimate the usual frequency of exposure for each transient risk factor. Person-time at risk was estimated for each transient exposure of interest by multiplying the self-reported average duration of each transient exposure by its frequency. Unexposed work time was derived by subtracting exposed time from the total amount of time worked that week by each participant.

A narrative text section of the interview collected open-ended information from participants on the circumstances of the injury-their own account of the tasks, tools, and occurrences at the time the injury occurred. This information was listed, sorted, and tallied to complement the categorical responses to better contextualize the injury circumstances.

Descriptive analyses were used to evaluate the demographic and occupational characteristics of the participating workers. The Mantel-Haenszel estimator for person-time data was used to estimate the RR and the corresponding 95\% CI for the transient exposures of interest. ${ }^{11-13}$ Workers were asked to report transient exposures just before the laceration injury and in the previous workweek. RRs were estimated using ratios of observed frequency of exposure during the hazard period to the expected (usual) frequency. This incidence rate ratio was interpreted as the risk of a sudden-onset laceration when exposed to the transient factor compared with the risk when unexposed. In addition, we assumed that each episode of tool sharpening would last $10 \mathrm{~s}$ and each episode of slipping and falling would last 1 min based on direct observations and conversations with plant staff. ${ }^{8,14}$ Stratified analyses were utilized to estimate the effects of gender, race/ethnicity, training, the number of adjacent coworkers, hours worked per week, and use of metal mesh gloves on each transient risk factor of interest. ${ }^{9}$ We used the Wald statistic to test for homogeneity across strata. ${ }^{15}$

The Institutional Review Board of the University of $\mathrm{Ne}$ braska-Lincoln and the Office of Human Research Administration of the Harvard School of Public Health approved all of the data collection procedures used in the study.

\section{RESULTS}

A total of 936 meatpacking workers experienced laceration injuries during the study period and 295 injured workers (32\%) were interviewed (Table 1).

The mean age of the workers was 36.6 years (SD 11.2). The majority of workers had a high school education (51\%), and $75 \%$ were men. The percentages of Caucasian, non-Hispanic and of Hispanic workers were similar: $48 \%$ and $45 \%$, respectively. The percentage of workers with tenure of $<1$ year was similar to that of workers with tenure of more than 4 years, $30 \%$ vs 33\%, respectively. Approximately $34 \%$ of workers reported having only onthe-job training, $7 \%$ had only classroom training, and 32\% had both classroom and on-the-job training.

Table 1. Characteristics of 295 meatpacking workers with a laceration injury at two Midwestern pork-processing plants, USA 2006-2009

\begin{tabular}{lc}
\hline Characteristic & $p$ value \\
\hline Age, years, mean (SD) & $36.6(11.2)$ \\
Education, years, mean (SD) & $11.1(6.1)$ \\
Grade school (1-8 years). $\mathrm{n}(\%)$ & $76(26)$ \\
High school (9-12 years). $(\%)$ & $149(51)$ \\
University ( $\geq 13$ years). $\mathrm{n}(\%)$ & $65(22)$ \\
Gender, female, $\mathrm{n}(\%)$ & $75(25.4)$ \\
Race/ethnicity, $\mathrm{n}(\%)$ & \\
Hispanic & $140(47.5)$ \\
Caucasian, non-Hispanic & $134(45.4)$ \\
Black & $12(4.1)$ \\
American-Indian/Alaskan Native & $1(0.3)$ \\
Asian & $4(1)$ \\
Refused/other & $4(1)$ \\
Upper extremity pain, numbness, tingling, $\mathrm{n}(\%)$ & $50(17.1)$ \\
Job experience, $\mathrm{n}$ (\%) & \\
S1 year & $88(30)$ \\
1-4 years & $76(25.8)$ \\
>4 years & $96(32.5)$ \\
Safety training & \\
None & $30(10.2)$ \\
Classroom only & $21(7.1)$ \\
On the job only & $100(33.9)$ \\
Both classroom and on the job & $93(31.5)$ \\
Other & $20(6.8)$ \\
\hline
\end{tabular}

* Totals do not add up to 295 due to missing data. 
Sixty workers $(20 \%)$ were recruited from the hot production side, $179(61 \%)$ from the cold production side, 23 (8\%) from the maintenance department and 16 (5\%) from quality assurance and/ or sanitation. A specific work location was not given for 17 workers.

Workers were asked to report all PPE items worn when the injury occurred and whether those items were required for their specific jobs (Table 2). For example, 147 workers (50\%) were required to wear cotton gloves; of these, $104(71 \%)$ wore them at the time of injury. Twenty-eight workers (10\%) were required to wear a metal mesh apron for torso protection; of these, $22(79 \%)$ wore it at the time of injury. Among the workers required to wear specific PPE items reported usage ranged from $79 \%$ of workers wearing the metal mesh apron to $60 \%$ wearing metal mesh gloves when the injury occurred (Table 2). These metal mesh gloves were the least utilized required item at the time of injury. Glove use was not examined as a transient risk factor in the casecrossover analyses because the majority of workers wore them while working; thus, the exposure remained fixed between the hazard and control periods.

Sharpening (RR 5.3, 95\% CI 3.8 to 7.4 ) and equipment malfunction ( $\mathrm{RR} 5.3,95 \% \mathrm{CI} 3.9$ to 7.3 ) were associated with the highest RRs for laceration injury, followed by using an unusual work method to accomplish a task (RR 4.1, 95\% CI 2.6 to 6.4 ) and performing an unusual task (RR 2.3, 95\% CI 1.8 to 3.0) (Table 3).

The reasons for malfunctioning equipment reported by 32 workers in the narrative text sections of the interview included new equipment $(n=5)$; jammed $(n=6)$; dull knives, blades, or hooks $(n=6)$; product fell or stuck $(n=2)$; sharp edges $(n=2)$; door or lid malfunction $(n=3)$; no gloves or machine guard $(n=2)$, and other $(n=6)$. Seventeen workers reported using unusual work methods; these included malfunctioning or new equipment $(n=3)$, difficulties keeping up with line speed $(n=3)$, different equipment or location on the line $(n=3)$, being new at the job $(\mathrm{n}=2)$, using a non-dominant hand $(\mathrm{n}=2)$, feeding product into machine differently $(n=1)$, product harder to process $(n=1)$ and cleaning or other $(n=2)$.

Sixty-six workers (22\%) reported that they were rushing just before the laceration injury occurred. Rushing was also the most frequently reported exposure independent of the hazard period prior to injury; workers reported rushing an average of 10.8 h per week (SD 15.6). Because rushing was frequently reported during both the control and the hazard periods, it was not significantly associated with the incidence rate of laceration injury (RR o.8, 95\% CI 0.7 to 1.1). Self-reported reasons for rushing (reported by 104 workers, including those not rushing at injury time) included line speed $(n=46)$; preparing to go home or on break $(n=15)$; pressure from supervisor and/or coworkers $(n=12)$;
Table 2. Type of personal protective equipment required and used at time of injury by 295 workers at two Midwestern pork-processing plants, 2006-2009

\begin{tabular}{|c|c|c|}
\hline $\begin{array}{l}\text { Personal } \\
\text { protective } \\
\text { equipment } \\
\text { (PPE) item } \\
\end{array}$ & $\begin{array}{r}\text { Number of workers } \\
\text { required to wear PPE } \\
\text { items for their specific } \\
\text { jobs/tasks, n }(\%)^{*}\end{array}$ & $\begin{array}{r}\text { Number of workers } \\
\text { who used the required } \\
\text { PPE items at injury } \\
\text { time, } \mathrm{n}(\%)^{\dagger}\end{array}$ \\
\hline Reusable gloves ${ }^{\ddagger}$ & $96(32.5)$ & $71(74.0)$ \\
\hline Disposable gloves $\ddagger$ & $105(35.6)$ & $81(77.1)$ \\
\hline Metal mesh gloves & 107 (36.3) & $64(59.8)$ \\
\hline Cotton gloves & $147(49.8)$ & $104(70.7)$ \\
\hline Plastic arm guard & $66(22.4)$ & $43(65.2)$ \\
\hline Metal mesh apron & $28(9.5)$ & $22(78.6)$ \\
\hline Rubber apron & $52(17.6)$ & $38(73.1)$ \\
\hline
\end{tabular}

* Percent of workers who were required to wear each PPE item was calculated from the total number of workers $I n=295$ ). Workers are required to wear more than one type of PPE so these percentages total to more than $100 \%$.

† Percent of workers who used each PPE item at the time of injury was calculated from the total number of workers required to wear each item.

$\ddagger$ Disposable gloves are similar to standard surgical gloves. Reusable gloves are made from thicker rubber and are similar to household cleaning gloves.

general rushing $(n=12)$; setting up the line or cleanup $(n=9)$; performing an unfamiliar task, unjamming or line delay $(n=7)$; understaffing $(n=3)$ and inexperience with work $(n=3)$.

Following rushing, performing an unusual task (45 workers, $15 \%$, RR 2.3, 95\% CI 1.8 to 3.0) and tool sharpening (44 workers, $15 \%$, RR $5 \cdot 3,95 \%$ CI 3.8 to 7.4 ) were the most frequently reported exposures just before the injury. Unusual tasks were reported by 43 workers and included machinery maintenance or repair $(n=7)$; unjamming $(n=6)$; job rotation or replacing another employee $(n=6)$; using a different machine or tool $(n=5)$; pushing or pulling product or containers $(n=5)$; cutting or sorting $(n=4)$; changing blades $(n=3)$; new task, job, or training another employee $(n=2)$; housekeeping $(n=2)$ and other $(n=3)$.

Being distracted was not significantly associated with the incidence rate of laceration injury (RR 1.1, 95\% CI o.6 to 1.9). Reasons for being distracted were reported by 27 workers and included line speed $(n=3)$, external factors such as looking around or noise $(n=7)$, talking with coworkers $(n=7)$, internal reasons such as thinking or being tired $(n=9)$, and removing gloves $(n=1)$.

Slipping was associated with an over 10o-fold increase in the risk of laceration injury, and falling was associated with an over 500o-fold increase in the risk of laceration injury (data not shown). Because both of these events occurred very infrequently (at injury time, 3\% of workers reported slipping and 3\% reported falling), the CIs for these estimates were very wide. Reasons for slipping or falling were reported by 15 workers and included floor

Table 3. Number of workers exposed to each transient risk factor, the number of hours exposed and the estimated RRs of laceration injury of 295 workers at two Midwestern pork-processing plants, 2006-2009

\begin{tabular}{lccc}
\hline Exposure & $\begin{array}{c}\text { Number of subjects } \\
\text { exposed just before } \\
\text { the injury, } \mathrm{n}(\%)\end{array}$ & $\begin{array}{c}\text { Number of hours } \\
\text { exposed in week prior } \\
\text { to injury, mean (SD) }\end{array}$ & $\mathrm{RR}(95 \% \mathrm{Cl})$ \\
\hline Sharpening & $44(15.0)$ & $2.1(6.7)$ & $5.3(3.8$ to 7.4$)$ \\
Equipment malfunction & $26(8.8)$ & $1.1(5.6)$ & $5.3(3.9$ to 7.3$)$ \\
Using unusual work method & $16(5.4)$ & $1.0(5.6)$ & $4.1(2.6$ to 6.4$)$ \\
Performing unusual task & $45(15.3)$ & $3.6(9.2)$ & $2.3(1.8$ to 3.0$)$ \\
Being tired & $25(8.5)$ & $3.5(8.5)$ & $1.2(0.8$ to 1.8$)$ \\
Being distracted & $13(4.4)$ & $1.9(6.9)$ & $1.1(0.6$ to 1.9$)$ \\
Rushing & $66(22.4)$ & $10.8(15.6)$ & $0.8(0.7$ to 1.1$)$ \\
\hline
\end{tabular}

* The estimated average number of hours included participants who reported zero hours of each exposure.

$\dagger$ The duration of each episode was assumed to last $10 \mathrm{~s}$. 
conditions such as fat or water $(n=5)$, working or walking $(n=4)$, ladder or scaffolding $(n=3)$, rushing $(n=2)$, and losing awareness $(n=1)$.

Stratified analyses were used to assess the modification of RRs associated with transient exposures by other factors: gender, ethnicity, safety training, number of employees on the line, hours worked per week and use of metal mesh gloves at the time of injury (Table 4).

There were several significant differences in the risk of laceration injury associated with using an unusual work method, tool sharpening, performing an unusual task, and being tired. The increase in laceration risk associated with using an unusual work method was higher for male workers than for female workers. The increase in the risk of laceration associated with tool sharpening was higher for Hispanic workers than for non-Hispanic workers. Although the risk of laceration injury associated with performing an unusual task was high for all workers, this increase was higher for non-Hispanic than for Hispanic workers. Surprisingly, being tired increased the risk of laceration injury for Hispanic workers yet it had a protective effect among nonHispanic workers (RR 3.9, 95\% CI 2.4 to 6.4 vs RR $0.36,95 \%$ CI 0.14 to 0.93$)$.

The increase in the risk of laceration injury associated with equipment malfunction was higher for workers with some training compared with those with no training (RR 6.6, 95\% CI 4.6 to 9.6 vs RR $1.8,95 \%$ CI 1.2 to 2.8 ) and for workers not wearing metal mesh gloves (RR 11. 7, 95\% CI 7. 7 to 17.8 vs RR 0.9, $95 \%$ $\mathrm{CI} 0.4$ to 1.8 ). In addition, the increase in the risk of laceration injury associated with performing an unusual task was higher for workers with one to two workers on the line next to them compared with workers who had more than two workers nearby.

\section{DISCUSSION}

This study evaluated the association of selected transient risk factors with the occurrence of laceration injuries in meatpacking workers. Results from the now-complete sample of 295 workers are presented to (1) corroborate our previously reported preliminary results from half the samples; (2) contextualize injury circumstances by evaluating narrative text reports in relation to categorical responses; (3) evaluate PPE use frequency among injured workers and (4) use the full sample to examine effect modification by potential effect modifiers such as gender, ethnicity, training, hours worked per week, and use of metal mesh gloves at the time of injury. The most salient transient risk factors are discussed below, followed by PPE use, and effect modification.

Tool sharpening, equipment malfunction, using an unusual work method to accomplish a task, performing an unusual task, slipping, and falling were associated with an increased risk of laceration injuries. Similar to our preliminary results, the RR estimates associated with slipping and falling were very large, had wide CIs, and appeared to be inflated because of the small sample size used to obtain these estimates $(n=10)$ (data not shown).

Sharpening and equipment malfunction were associated with the highest RR for laceration injury. Knife and tool sharpening is first performed by an expert mechanic at the knife department. Workers receive sharp knives before beginning their shift. Because many tasks involve repetitive cuts of chilled product over the course of the shift, continuous knife and tool sharpening is still required. Some of the knife sharpening devices are overhead and require reaching up and then back down to the product. We suspect that knife-sharpening frequency differs by worker preference and type of job. The advantage to the case- crossover design is that these differences are controlled for by using a within-person analytic approach to estimate RR. Newly sharpened tools pose a significant risk for a laceration injury due to blade sharpness; however, the force required to perform specific cuts on a chilled meat product may be reduced with increased blade sharpness. Lower force to perform repetitive tasks may in turn reduce the incidence of repetitive strain injuries. ${ }^{16,17}$ Beyond the clear associations of cut injuries to knife sharpening found here, we were not able to narrow down the exact circumstances of knife sharpening that result in injury risk. Further ergonomic and observational research focusing on knife sharpening is needed to reduce the risks associated with this fairly common exposure (occurring an average of $2.1 \mathrm{~h}$ in the week before the injury, range o-6o h).

Equipment malfunction was associated with a more than fivefold increase in the RR of laceration injuries. Malfunctioning equipment was attributed to newness, jamming, dull equipment, and other, which emphasizes the importance of continued maintenance. Particular attention to new equipment performance and routine maintenance as a standard administrative practice may help avoid equipment malfunctioning and therefore reduce laceration injury risks.

The risk of laceration injury associated with an unusual work method to accomplish a task was 4.1 (95\% CI 2.6 to 6.4). This has been reported in other studies and is consistent with our preliminary results. ${ }^{8,9}$ Reasons for using an unusual work method included malfunctioning, new or different equipment, line speed, different location on the line, inexperience on the job, or different product. Work methods change for numerous reasons, and one approach to prevention is to increase cross-training in handling unusual work exposures or changing work locations and using different equipment to do the same task. Training workers and supervisors on alternative safe approaches to complete work when circumstances are different from usual may be important to add to safety training, both on the job and in the classroom.

The RR of laceration injury associated with performing an unusual task was 2.3 (95\% CI 1.8 to 3.o) compared with 3.7 (95\% CI 2.6 to 5.2) reported in our preliminary results. Performing these tasks has been reported previously as a risk factor for other occupational injuries.9,11 Reasons for these lacerations included machinery maintenance or repair, unjamming, job rotation, using a different machine or tool, pushing or pulling product or containers, cutting or sorting, changing blades, performing a new task or job, training another employee, and housekeeping. Considering the overlaps among the reported reasons for laceration injuries associated with malfunctioning equipment, using an unusual work method and performing an unusual task, careful evaluation of the multiple unexpected changes in work tracking and patterns and evaluating administrative means that attempt to decrease unexpected changes are needed to reduce cut injuries in this highly mechanized and routinized working environment.

Worker-related factors such as being tired, rushing, and being distracted trended towards increases in laceration injury risks (Table 3). These increases, however, were not statistically significant, which is also similar to our preliminary results. Rushing appeared to be universal in both plants due to the generally fast-paced nature of the food-processing environment. ${ }^{18}$ Rushing was the most frequently reported transient exposure in the control period (10.8 h per week, SD 15.6) and just before the laceration injury (66 workers, $22 \%$ ); it was attributed primarily to line speed, getting ready to leave the line to go on break or 
Table 4. Stratified transient exposures and RRs of laceration injury of 295 workers at two Midwestern pork-processing plants, $2006-2009$

\begin{tabular}{|c|c|c|c|c|c|c|c|}
\hline \multirow[b]{2}{*}{ Exposure } & \multicolumn{4}{|c|}{ Male $(n=218)$} & \multicolumn{3}{|l|}{ Female $(n=75)$} \\
\hline & \multicolumn{2}{|c|}{$\begin{array}{r}\text { Number of subjects } \\
\text { exposed just before } \\
\text { the injury, n (\%) }\end{array}$} & \multirow[t]{2}{*}{$\begin{array}{l}\text { Number of hours } \\
\text { exposed in week prior } \\
\text { to injury, mean (SD)* }\end{array}$} & \multirow[t]{2}{*}{$\mathrm{RR}(95 \% \mathrm{Cl})$} & \multirow[t]{2}{*}{$\begin{array}{r}\text { Number of subjects } \\
\text { exposed just before } \\
\text { the injury, n (\%) }\end{array}$} & \multirow[t]{2}{*}{$\begin{array}{r}\text { Number of hours } \\
\text { exposed in week prior } \\
\text { to injury, mean }(S D)^{*}\end{array}$} & \multirow[t]{2}{*}{$\mathrm{RR}(95 \% \mathrm{Cl})$} \\
\hline \multicolumn{3}{|l|}{ A. Gender } & & & & & \\
\hline \multicolumn{2}{|l|}{ Sharpening ${ }^{\dagger}$} & $32(15.0)$ & $2.3(7.2)$ & 5.5 (3.7 to 8.1$)$ & $12(16.0)$ & $1.8(4.9)$ & $5.0(2.8$ to 9.1$)$ \\
\hline \multicolumn{2}{|l|}{ Equipment malfunction } & $20(9.2)$ & $1.1(5.5)$ & 6.6 (4.5 to 9.8$)$ & $6(8.0)$ & $1.2(6.2)$ & 3.5 (2.1 to 5.8$)$ \\
\hline \multicolumn{2}{|c|}{ Using unusual work method } & $14(6.4)$ & $1.1(5.9)$ & $6.4(3.5 \text { to } 11.8)^{\ddagger}$ & $2(2.7)$ & $0.7(4.7)$ & $1.4(0.7 \text { to } 2.8)^{\ddagger}$ \\
\hline \multicolumn{2}{|c|}{ Performing unusual task } & $34(15.6)$ & $3.9(9.7)$ & $2.2(1.7$ to 2.9$)$ & $11(14.7)$ & $2.8(7.7)$ & 2.9 (1.7 to 5.0$)$ \\
\hline \multicolumn{2}{|l|}{ Being tired } & $15(6.8)$ & $3.5(8.4)$ & $0.9(0.51$ to 1.6$)$ & $10(13.3)$ & $3.7(8.6)$ & 1.9 (1.1 to 3.3$)$ \\
\hline \multicolumn{2}{|l|}{ Being distracted } & $9(4.1)$ & $1.4(5.1)$ & $1.6(0.8 \text { to } 3.5)^{\ddagger}$ & $3(4.0)$ & $1.4(5.1)$ & $0.3(0.09 \text { to } 0.8)^{\ddagger}$ \\
\hline Rushing & & $50(22.9)$ & $10.1(14.9)$ & $1.0(0.8 \text { to } 1.4)^{\ddagger}$ & $15(20.0)$ & $13.3(17.4)$ & $0.44(0.28 \text { to } 0.72)^{\ddagger}$ \\
\hline \multirow[b]{2}{*}{ Exposure } & \multicolumn{4}{|c|}{$\underline{\text { Hispanic }(n=140)}$} & \multicolumn{3}{|l|}{ Non-Hispanic $(\mathrm{n}=136)$} \\
\hline & \multicolumn{2}{|c|}{$\begin{array}{l}\text { Number of subjects } \\
\text { exposed just before } \\
\text { the injury, n (\%) }\end{array}$} & $\begin{array}{l}\text { Number of hours } \\
\text { exposed in week prior } \\
\text { to injury, mean (SD)* }\end{array}$ & $\mathrm{RR}(95 \% \mathrm{Cl})$ & $\begin{array}{r}\text { Number of subjects } \\
\text { exposed just before } \\
\text { the injury, } n(\%)\end{array}$ & $\begin{array}{l}\text { Number of hours } \\
\text { exposed in week prior } \\
\text { to injury, mean }(S D)^{*}\end{array}$ & $\operatorname{RR}(95 \% \mathrm{Cl})$ \\
\hline \multicolumn{8}{|l|}{ B. Ethnicity } \\
\hline \multicolumn{2}{|l|}{ Sharpening ${ }^{\dagger}$} & $35(25.0)$ & $3.1(6.7)$ & $7.6(4.9 \text { to } 11.8)^{\ddagger}$ & $5(3.7)$ & $1.4(6.9)$ & $1.3(0.75 \text { to } 2.4)^{\ddagger}$ \\
\hline \multicolumn{2}{|l|}{ Equipment malfunction } & $13(9.3)$ & $1.7(7.1)$ & $3.4(2.3 \text { to } 5.0)^{\ddagger}$ & $10(7.4)$ & $0.7(4.0)$ & $9.0(4.9 \text { to } 16.6)^{\ddagger}$ \\
\hline \multicolumn{2}{|c|}{ Using unusual work method } & $4(2.9)$ & $0.5(3.4)$ & $4.5(1.3$ to 15.4$)$ & $12(8.8)$ & $1.3(6.7)$ & 7.0 (3.8 to 12.7$)$ \\
\hline \multicolumn{2}{|c|}{ Performing unusual task } & $19(13.6)$ & $4.1(10.6)$ & $1.6(1.2 \text { to } 2.1)^{\ddagger}$ & $24(17.6)$ & $3.1(7.5)$ & $3.8(2.5 \text { to } 5.8)^{\ddagger}$ \\
\hline \multicolumn{2}{|l|}{ Being tired } & $19(13.6)$ & $3.0(9.1)$ & $3.9(2.4 \text { to } 6.4)^{\ddagger}$ & $6(4.4)$ & $4.1(7.7)$ & $0.4(0.1 \text { to } 0.9)^{\ddagger}$ \\
\hline \multicolumn{2}{|l|}{ Being distracted } & $1(0.7)$ & $0.2(1.0)$ & $1.8(0.27$ to 11.6$)$ & $12(8.8)$ & $3.8(9.7)$ & $1.1(0.60$ to 1.9$)$ \\
\hline \multicolumn{2}{|l|}{ Rushing } & $25(17.9)$ & $10.1(15.9)$ & $0.5(0.4 \text { to } 0.8)^{\ddagger}$ & $39(28.7)$ & $12.0(15.4)$ & $1.2(0.87 \text { to } 1.7)^{\ddagger}$ \\
\hline
\end{tabular}

\begin{tabular}{|c|c|c|c|c|c|c|c|}
\hline Exposure & \multicolumn{4}{|c|}{ No training $(n=30)$} & \multicolumn{3}{|l|}{ Any training $(n=265)$} \\
\hline \multicolumn{8}{|l|}{ C. Training } \\
\hline \multirow{2}{*}{\multicolumn{2}{|c|}{$\begin{array}{l}\text { Sharpening }^{\dagger} \\
\text { Equipment malfunction }\end{array}$}} & $3(10.0)$ & $1.1(2.8)$ & $5.4(1.4$ to 20.3$)$ & $41(15.5)$ & $2.3(7.0)$ & $5.3(3.8$ to 7.4$)$ \\
\hline & & $3(10.0)$ & $2.7(9.7)$ & $1.8(1.2 \text { to } 2.8)^{\ddagger}$ & $23(8.7)$ & $1.0(5.0)$ & $6.6(4.6 \text { to } 9.6)^{\ddagger}$ \\
\hline \multicolumn{2}{|c|}{ Using unusual work method } & $5(16.7)$ & $1.9(7.4)$ & $4.4(2.7$ to 7.1$)$ & $11(4.2)$ & $0.9(5.4)$ & $4.0(2.1$ to 7.6$)$ \\
\hline \multicolumn{2}{|l|}{ Being distracted } & $0(0)$ & $1.8(3.8)$ & - & $13(4.9)$ & $1.9(7.2)$ & 1.3 (0.76 to 2.2$)$ \\
\hline Rushing & & $7(23.3)$ & $14.6(17.8)$ & $0.3(0.1$ to 0.9$)$ & $59(22.3)$ & $10.4(15.3)$ & $0.9(0.7$ to 1.2$)$ \\
\hline \multirow[b]{2}{*}{ Exposure } & \multicolumn{4}{|c|}{$1-2$ workers on the line $(n=71)$} & \multicolumn{3}{|c|}{$>2$ workers on the line $(n=174)$} \\
\hline & \multicolumn{2}{|c|}{$\begin{array}{r}\text { Number of subjects } \\
\text { exposed just before } \\
\text { the injury, } n(\%)\end{array}$} & $\begin{array}{r}\text { Number of hours } \\
\text { exposed in week prior } \\
\text { to injury, mean (SO)* }\end{array}$ & $\mathrm{RR}(95 \% \mathrm{Cl})$ & $\begin{array}{r}\text { Number of subjects } \\
\text { exposed just before } \\
\text { the injury, } \mathrm{n}(\%)\end{array}$ & $\begin{array}{l}\text { Number of hours } \\
\text { exposed in week prior } \\
\text { to injury, mean (SO)* }\end{array}$ & $\mathrm{RR}(95 \% \mathrm{Cl})$ \\
\hline \multicolumn{2}{|c|}{ Using unusual work method } & $2(2.8)$ & $0.5(2.0)$ & $3.0(0.68$ to 13.4$)$ & $7(4.0)$ & $0.6(3.7)$ & $5.0(2.5$ to 10.0$)$ \\
\hline \multicolumn{2}{|c|}{ Performing unusual task } & $11(15.5)$ & $1.9(4.6)$ & $7.3(3.3 \text { to } 15.9)^{\ddagger}$ & $19(10.9)$ & $4.0(10.3)$ & $1.2(0.92 \text { to } 1.7)^{\ddagger}$ \\
\hline \multicolumn{2}{|c|}{ Being tired } & $3(4.2)$ & $2.0(5.4)$ & $1.1(0.29$ to 3.9$)$ & $16(9.2)$ & $3.9(9.1)$ & $1.1(0.70$ to 1.8$)$ \\
\hline \multicolumn{2}{|l|}{ Being distracted } & $6(8.5)$ & $4.1(11.5)$ & $1.1(0.43$ to 2.6$)$ & $4(2.3)$ & $1.0(3.6)$ & $0.9(0.4$ to 1.9$)$ \\
\hline Rushing & & $20(28.2)$ & $12.1(17.1)$ & $1.4(0.82$ to 2.2$)$ & $35(20.1)$ & $9.5(14.7)$ & 0.8 (0.6 to 1.2$)$ \\
\hline & $\leq 45 \mathrm{~h} / \mathrm{v}$ & veek $(n=147)$ & & & $>45 \mathrm{~h} /$ week $(\mathrm{n}=148)$ & & \\
\hline Exposure & $\begin{array}{r}\text { Number } \\
\text { exposed } \\
\text { the } \mathrm{i}\end{array}$ & $\begin{array}{l}\text { of subjects } \\
\text { just before } \\
\text { njury, } \mathrm{n}(\%)\end{array}$ & $\begin{array}{r}\text { Number of hours } \\
\text { exposed in week prior } \\
\text { to injury, mean (SD)* }\end{array}$ & $\mathrm{RR}(95 \% \mathrm{Cl})$ & $\begin{array}{r}\text { Number of subjects } \\
\text { exposed just before } \\
\text { the injury, } n(\%)\end{array}$ & $\begin{array}{r}\text { Number of hours } \\
\text { exposed in week prior } \\
\text { to injury, mean (SD)* }\end{array}$ & $\mathrm{RR}(95 \% \mathrm{Cl})$ \\
\hline E. Hours per week & & & & & & & \\
\hline Sharpening ${ }^{\dagger}$ & & $25(17.0)$ & $2.4(7.0)$ & 5.9 (3.5 to 9.8$)$ & $19(12.8)$ & $1.8(6.4)$ & 4.8 (3.2 to 7.3$)$ \\
\hline Equipment malfunctio & & $17(11.6)$ & $1.5(6.6)$ & $6.3(4.1$ to 9.5$)$ & $9(6.1)$ & $0.7(4.5)$ & $4.4(2.8$ to 7.0$)$ \\
\hline
\end{tabular}


Table 4. Continued

\begin{tabular}{|c|c|c|c|c|c|c|c|}
\hline \multirow[b]{2}{*}{ Exposure } & \multicolumn{4}{|c|}{ No metal mesh gloves at injury time $(n=230)$} & \multicolumn{3}{|c|}{ Metal mesh gloves at injury time $(n=65)$} \\
\hline & \multicolumn{2}{|c|}{$\begin{array}{r}\text { Number of subjects } \\
\text { exposed just before } \\
\text { the injury, } \mathrm{n}(\%)\end{array}$} & \multirow[t]{2}{*}{$\begin{array}{l}\text { Number of hours } \\
\text { exposed in week prior } \\
\text { to injury, mean (SD) }\end{array}$} & \multirow[t]{2}{*}{ RR $(95 \% \mathrm{Cl})$} & \multirow[t]{2}{*}{$\begin{array}{r}\text { Number of subjects } \\
\text { exposed just before } \\
\text { the injury, } n(\%)\end{array}$} & \multirow[t]{2}{*}{$\begin{array}{l}\text { Number of hours } \\
\text { exposed in week prior } \\
\text { to injury, mean (SD)* }\end{array}$} & \multirow[t]{2}{*}{$\operatorname{RR}(95 \% \mathrm{Cl})$} \\
\hline \multicolumn{3}{|l|}{ F. Gloves } & & & & & \\
\hline Sharpening $^{\dagger}$ & & $14(6.1)$ & $1.1(5.3)$ & $3.8(2.2$ to 6.5$)$ & $30(46.2)$ & $5.8(9.3)$ & $6.6(4.3$ to 9.9$)$ \\
\hline Equipment malfunct & & $23(10.0)$ & $0.9(4.5)$ & $11.7(7.7 \text { to } 17.8)^{\ddagger}$ & $3(4.6)$ & $2.1(8.4)$ & $0.9(0.4 \text { to } 1.8)^{\ddagger}$ \\
\hline Using unusual work & method & $13(5.7)$ & $1.0(5.8)$ & $4.2(2.6$ to 6.7$)$ & $3(4.6)$ & $0.9(4.9)$ & $3.7(1.1$ to 13.3$)$ \\
\hline Being distracted & & $12(5.2)$ & $2.2(7.3)$ & $1.2(0.7$ to 2.0$)$ & $1(1.5)$ & $0.8(5.1)$ & - \\
\hline Rushing & & $50(21.7)$ & $10.0(14.9)$ & $1.0(0.7 \text { to } 1.2)^{\ddagger}$ & $16(24.6)$ & $13.6(17.5)$ & $0.4(0.2 \text { to } 0.82)^{\ddagger}$ \\
\hline
\end{tabular}

* The estimated average number of hours included participants who reported zero hours of each exposure; some subjects had missing demographic data so totals do not all add to 295 .

$\dagger$ The duration of each episode was assumed to last $10 \mathrm{~s}$.

$\ddagger$ Differences among strata were statistically significant.

home, and pressure from management. These results should be interpreted with caution. While we found no statistically significant association between rushing and the risk of laceration injury, it was self-reported as the reason for injury in many cases. Because rushing was very frequent, it is possible that using the previous workweek as a control period was not ideal to capture the risk of laceration injury associated with rushing. Perhaps using another time frame such as the previous hour prior to injury would help to better capture real-time changes in rushing and how they relate to injuries. In addition, we were unable to tease out interactions among transient exposures of interest such as rushing, performing unusual tasks, and equipment malfunction. For example, reasons for being distracted included talking, looking around, and thinking or being tired. This overlap indicates that some of the risk factors may be occurring simultaneously and should be evaluated as such in future studies. We did not evaluate line speed objectively in this study; we relied on self-reports in which line speed was reported as a reason for rushing and being distracted just before the laceration injury.

PPE is intended to protect workers while they perform their job tasks. The required PPE items vary by job and department according to specific tasks and safety hazards. For example, several layers of gloves are worn on the cold production side for warmth and to prevent occupational injuries. These items are only worn during line work. During a 15 min break, workers remove all PPE items, rest, return to their line and don all PPE items again before starting their work. Because nearly $95 \%$ of all lacerations are to the fingers or hands versus the arm or torso, the most important aspect of PPE used in this work environment may be the cut resistance of the gloves themselves and employees' preferences for their use. Although supervisors are careful to monitor that all the required PPE is worn, workers occasionally omit some PPE items for comfort while working. For example, with cotton gloves weighing $2 \mathrm{oz}$, metal mesh $7.5 \mathrm{oz}$, and reusable gloves $3 \mathrm{oz}$, a worker could have an additional weight of $12.5 \mathrm{oz}$ while working. To estimate the proportion of the required PPE items that was actually being worn at the time of laceration injury, we used a checklist of all PPE items to prevent recall bias. More than $60 \%$ of workers reported wearing the required items at the time of their laceration injuries; this suggests that (1) PPE use is high but full compliance is not being realized and (2) injuries still happen when PPE is being worn. By item, the lowest usage at time of injury was for metal mesh gloves (6o\%) and the highest reported usage was for metal mesh aprons (79\%). A detailed evaluation of the reasons for not wearing the required PPE and how injuries still occur when all required PPE is used is needed to better prevent lacerations. Additional issues in this work environment that need to be examined include the weight of gloves, comfort, fatigue by glove type, and cut resistance.

Gender, ethnicity, safety training, number of workers on the line, and wearing metal mesh gloves at injury time modified the effects of transient exposures on the risk of laceration injury. We found several significant differences among strata even with small sample sizes available for some of the comparisons. Stratified analyses were not adjusted for multiple comparisons and some associations within each stratum may be significant by chance alone. Also, the test of homogeneity across strata may have been underpowered due to the nature of the test. ${ }^{15}$ Laceration risk associated with using an unusual work method was higher for men than for women. Tool sharpening risk was higher for Hispanic than for non-Hispanic workers. The risk of laceration injury associated with equipment malfunction and performing an unusual task was higher for non-Hispanic workers. Surprisingly, being tired increased the risk of laceration injury for Hispanic workers yet it was associated with a reduced RR among non-Hispanic workers. Gender and Hispanic ethnicity may be markers of unmeasured differences in exposures that need to be examined further.

Safety training appeared to significantly increase the risk of injury associated with equipment malfunction while having no training increased the risk to a much smaller degree (RR 6.6, $95 \%$ CI 4.6 to 9.6 vs RR $1.8,95 \%$ CI 1.2 to 2.8 ). Learning to work or deal with malfunctioning equipment may require more extensive training than is typically provided to workers. ${ }^{9}$ Cursory training may introduce a false sense of security and confidence that may, in fact, increase the risk of occupational injury.

Interestingly, the increase in the risk of laceration injury associated with performing an unusual task was higher with fewer workers on the line (one to two workers on the line next to the injured participant) compared with workers with two or more workers nearby. Line crowding does not appear to modify the risk of laceration, and having more workers on the line might help deal with unusual events such as performing an unusual task. Additional evaluation of the safety training curricula and the number of workers on the line would be beneficial to understand the differences in the effect modification of lacerations associated with these factors.

The research question that a case-crossover study addresses is: Did anything unusual occur just before the onset of the injury or symptom? Thus, this particular design is best suited for identifying non-random transient changes that occur before nonrandom outcomes such as occupational laceration injuries. For 
example, when a production worker decides to either fix or operate malfunctioning equipment (which may occur only once per month), our data suggest that this transient exposure increases the risk of an injury at that time. Questions must be asked that determine the frequency and duration of those exposures and whether or not the exposure existed at the time of the injury. Exposures that are fixed for intermediate or lengthy time intervals within an individual-for example, age or occupation-cannot be assessed using the case-crossover design.

Recall bias has been cited as a potentially important limitation in case-crossover studies. ${ }^{12,19}$ A bias away from the null hypothesis of no association between transient risk factors and laceration injuries may occur if exposures just before the injury are overestimated and exposures in the previous workweek are underestimated. ${ }^{20}$ We previously reported results from a brief reliability assessment showing that the reliability of workers' recall of transient exposures was found to be moderate to high. ${ }^{8}$ Because only 37 workers participated in the reliability study, more extensive reliability assessment is needed to address this bias fully.

Validity of workers' recall has also been questioned. Our previous work in this setting attempted to validate workers' reported exposures on the line by observing 136 uninjured workers for 60 min each and subsequently interviewing them (within 8 days) about exposures during the observation period. ${ }^{14}$ Excellent agreement was found between observed and reported work location, task, and tools. Agreement between observed and reported PPE use varied from excellent to poor for various items. Excellent agreement was found for tool sharpening, good agreement for occurrence of break during the observation period, and poor agreement for other exposures that occurred infrequently such as slipping and falling. ${ }^{14}$

Several transient risk factors may occur simultaneously. For example, a worker may be performing unusual tasks while dealing with malfunctioning equipment and rushing. It will be necessary to conduct a larger study to evaluate these interactions. The effect of other potential transient risk factors-such as medications, alcohol, sleep, and depression-on the risk of laceration and other occupational injuries should also be evaluated in future studies. Future intervention studies should focus on structural and operational changes suggested by these findings that would eliminate transient exposures associated with laceration injury.

The case-crossover study design was useful for evaluating associations between transient exposures and lacerations because they are acute onset injuries. However, there were limitations to the usual frequency approach to defining the control period. For some exposures, workers had difficulty recalling frequencies in the previous workweek, it limited our ability to capture variability in rushing and PPE use. A different control period, $2 \mathrm{~h}$ prior to the injury, for example, needs further consideration. Other information sources to estimate exposures in the control period also need consideration, such as plant records of the number of workers on the line and line speed.

\section{CONCLUSIONS}

This is the largest case-crossover study to date to evaluate the risk of occupational laceration injuries in meat packing.

Our results confirm our prior preliminary findings that sharpening tools, equipment malfunction, using an unusual work method to accomplish a task, and performing an unusual task are important risk factors for laceration injuries in this linepaced work environment. Novel findings from the results of this full study include that these transient risk factors vary by gender, ethnicity, training, and number of workers on the line. Also, we observed high PPE compliance at the time of the injury. Meatpacking laceration injuries have not been well studied previously, and sharpening as a laceration risk factor emerges as a novel finding in this industry. Detailed analysis of sharpening protocols, expanded training in unusual work circumstances, and sources of PPE failure are all needed to effectively reduce laceration injuries in the meatpacking industry.

Acknowledgments - The authors thank reviewers for thoughtful comments. The assistance of Farmland Foods, Inc. occupational health staff, management and supervisors was greatly appreciated. Thank you to all the workers who participated. This work was supported by grant Ro1 OHoo8174 (NIOSH, MJP, PI). Ethical approval was provided by the Institutional Review Board of the University of Nebraska-Lincoln and the Office of Human Research Administration of the Harvard School of Public Health.

Contributors - LL developed data collection tools and data analysis plan. LL monitored data collection and analyzed data for the study. She drafted and revised the manuscript. She is guarantor. GS conceptualized the study, developed data analysis plan, critically reviewed and revised the manuscript drafts. TLS conceptualized the study, monitored data collection, critically reviewed and revised the manuscript drafts. MM assisted with data analysis plan and critically reviewed and revised the manuscript drafts. MJP conceptualized the study, secured funding for the study, developed data collection tools and data analysis plan. MJP critically reviewed and revised the manuscript drafts.

\section{REFERENCES}

1. Bureau of Labor Statistics. 2009. http://www.bls.gov/iif/oshwc/osh/os/ ostb2435.pdf (accessed May 5, 2011).

2. Hagberg M, Christiani D, Courtney TK, et al. Conceptual and definitional issues in occupational injury epidemiology. Am J Ind Med 1997;32:106-15.

3. Sorock GS, Smith E, Hall N. Hospitalized occupational finger amputations, New Jersey, 1985 and 1986. Am J Ind Med 1993;23:439-47.

4. Jackson LL. Non-fatal occupational injuries and illnesses treated in hospital emergency departments in the United States. In) Prev 2001;7(Suppl 1):i21-6.

5. Lombardi DA, Sorock GS, Holander L, et al. A case-crossover study of transient risk factors for occupational hand trauma by gender. J Occup Environ Hyg 2007;4:790-7.

6. Cai C, Perry MJ, Sorock GS, et al. Laceration injuries among workers at meat packing plants. Am J Ind Med 2005;47:403-10.

7. Culp K, Brooks M. Rupe K, et al. Traumatic injury rates in meatpacking plant workers. J Agromedicine 2008;13:7-16.

8. Lander L, Sorock GS, Stentz TL, et al. A case-crossover study of occupational laceration injuries in pork processing: methods and preliminary findings. Occup Environ Med 2010;67:686-92.

9. Sorock GS, Lombardi DA, Hauser R, et al. A case-crossover study of transient risk factors for occupational acute hand injury. Occup Environ Med 2004;61:305-11.

10. Bell JL, MacDonald LA. Hand lacerations and job design characteristics in line-paced assembly. J Occup Environ Med 2003;45:848-56.

11. Sorock GS, Lombardi DA, Gabel CL, et al. Case-crossover studies of occupational trauma: methodological caveats. In) Prev 2001;7 (Suppl 1) :i38-42.

12. Sorock GS, Lombardi DA, Hauser RB, et al. A case-crossover study of occupational traumatic hand injury: methods and initial findings. Am J Ind Med 2001;39: 171-9.

13. Rothman K, Greenland S. Modern Epidemiology. 2nd edn. Philadelphia, PA: Lippincott-Raven Publishers, 1998:269-75.

14. Lander L, Sorock G, Stentz TL, et al. Validation of self-reported occupational exposures in meatpacking workers. Am J Ind Med 2009;52:707-15.

15. Rothman K. Greenland S, Lash T. Modern Epidemiology. 3rd edn. Philadelphia, PA: Lippincott Williams \& Wilkins, 2008:279-80.

16. McGorry RW, Dowd PC, Dempsey PG. Cutting moments and grip forces in meat cutting operations and the effect of knife sharpness. Appl Ergon 2003;34:375-82.

17. McGorry RW, Dowd PC, Dempsey PG. The effects of blade finish and blade edge angle on forces used in meat cutting operations. Appl Ergon 2005;36:71-7.

18. Quandt SA, Grzywacz JG, Marin A, et al. Illnesses and injuries reported by Latino poultry workers in western North Carolina. Am J Ind Med 2006;49:343-51.

19. Maclure M. The case-crossover design: a method for studying transient effects on the risk of acute events. Am J Epidemio/1991;133:144-53.

20. Mittleman MA, Maclure M, Robins JM. Control sampling strategies for case-crossover studies: an assessment of relative efficiency. $A m \mathrm{~J}$ Epidemio/1995;142:91-8. 